\title{
Rotor Position and Speed Estimation of Interior Permanent Magnet Synchronous Motor using Unscented Kalman Filter
}

\author{
Lu An *, and Kay Hameyer *
}

\begin{abstract}
This paper proposes the rotor position and rotor speed estimation for an interior permanent magnet synchronous machines (IPMSM) using Unscented Kalman Filter (UKF) in alpha-beta coordinate system. Conventional algorithms using UKF are based on the simple observer model of IPMSM in d-q coordinate system. Rotor acceleration is neglected within the sampling step. An expansion of the observer model in an alpha-beta coordinate system with the consideration of the rotor speed variation provides the improved rotor position and speed estimation. The results show good stability concerning the expansion of observer model for the IPMSM.
\end{abstract}

\section{Keywords: Rotor position, IPMSM, Unscented Kalman Filter, Estimation}

\section{Introduction}

An exact rotor position is required to control the PMSMs, which can be obtained by installing an encoder on the rotor shaft. However, the cost will be increased. Therefore, an encoderless control with position observer is designed to provide the information about exact rotor position, which plays an important role in industry applications [3]. It has three important benefits:

1. The system costs can be significantly reduced, since the hardware components can be saved.

2. Low installation space requirement

3. Less electromagnetic compatibility problems.

In literatures, an Extended Kalman Filter concept (EKF) $[1,6]$ provides the speed estimation without the common approach of signal injection. However, its computational complexity for the calculation of the Jakobian matrix and the instability due to the linearization are the disadvantages of the EKF.

The UKF is suitable for the state estimation of a nonlinear system $[10,14]$. The linearization for a non-linear system is not required in comparison to the Extended Kalman Filter (EKF). In literature [2], the observer model of IPMSMs by using UKF is reduced, e.g.: the dynamic changes of the rotor speed at load operation or the disturbance in mechanical system during the speed response. This paper introduces a new extension of rotor position and rotor speed estimation for IPMSM, which is based on the

\footnotetext{
* Institute of Electrical Machines, RWTH Aachen University

Schinkelstr. 4, 52062 Aachen Germany (Lu.An@iem.rwthaachen.de)

Received 11 October 2014; Accepted 29 November 2014
}

UKF and combines a disturbance observer.

The paper is organized as follows: section III gives a description of the encoderless speed control structure. In section IV the information about the expansion of the observer model can be found. Section V: the experiment results are presented. In section VI, the Conclusion is given.

\section{Encoderless Speed Control}

A block diagram representation for a field oriented control of IPMSM, which uses a voltage regulated space vector PWM voltage source inverter is shown in Fig. 1.

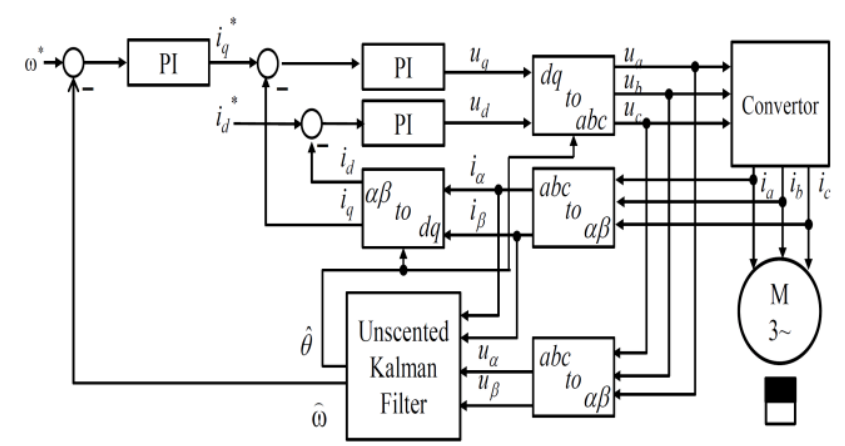

Fig. 1. Encoderless speed control scheme

It consists of a current control loop and a speed control loop, which are linked with each other. The output iq* of the speed controller is used as the reference variable for the iq current controller. Due to the linear independence of the stator currents in $\mathrm{dq}$ coordinates, the two current components id and iq can be controlled separately. More detailed information will be given in the following chapters. 
The estimated rotor position $\theta \mathrm{el}$ is used for the Park's transformation. Thus, the currents $i \alpha$ and $i \beta$ can be transformed into id and iq, and the estimated speed $\omega$ mech is fed back to the speed control [8].

\section{Expansion of the Observer Model for IPMS}

The observer model of the IPMSM, which is based on the mathematical model in alpha-beta coordinate system (1), (2) [1], is extended in this paper. Thereby, the change in the rotor speed of the machine in load operation is accurately considered (3) [5], [11]. A disturbance variable Sdis, which is regarded as constant during the sampling time step, specifies the parameter impreciseness of the machine model and the disturbance of the mechanical system in load operation (3) and (5).

The observer equation $f(x(t), u(t))$ for the continuous system can be represented by

$$
\begin{gathered}
\frac{d i_{\alpha}}{d t}=a_{1} i_{\alpha}+a_{2} i_{\beta}+a_{3} \omega_{e l}+b_{1} u_{\alpha}+b_{2} u_{\beta}, \\
\frac{d i_{\beta}}{d t}=a_{4} i_{\alpha}+a_{5} i_{\beta}+a_{6} \omega_{e l}+b_{3} u_{\alpha}+b_{4} u_{\beta}, \\
\frac{d \omega_{e l}}{d t}=\frac{3 p^{2}}{2 J}\left(\cos \theta_{e l} \cdot i_{\beta}-\sin \theta_{e l} \cdot i_{\alpha}\right)\left[\psi_{P M}\right. \\
\left.+\left(L_{d}-L_{q}\right)\left(\cos \theta_{e l} \cdot i_{\alpha}+\sin \theta_{e l} \cdot i_{\beta}\right)\right], \\
-\frac{p}{J}\left(B \frac{\omega_{e l}}{p}+T_{l o a d}-S_{d i s}\right) \\
\frac{d \theta_{e l}}{d t}=\omega_{e l}, \\
\frac{d S_{d i s}}{d t}=0
\end{gathered}
$$

and the output equation is given by

$$
y(t)=\left[\begin{array}{lllll}
1 & 0 & 0 & 0 & 0 \\
0 & 1 & 0 & 0 & 0
\end{array}\right] \cdot\left[\begin{array}{lllll}
i_{\alpha} & i_{\beta} & \omega_{e l} & \theta_{e l} & S_{\mathrm{dis}}
\end{array}\right]^{T},
$$

where

$$
\begin{gathered}
a_{1}=\left(-R L_{\beta}+\omega_{e l} L_{\alpha} L_{\alpha \beta}+\omega_{s} L_{\beta} L_{\alpha \beta}\right) / L_{2}, \\
a_{2}=\left(R L_{\alpha \beta}-\omega_{e l} L_{\alpha} L_{\beta}+\omega_{e l} L_{\beta}^{2}+2 \omega_{e l} L_{\alpha \beta}^{2}\right) / L_{2}, \\
a_{3}=\left(L_{\beta} \psi_{P M} \sin \theta_{e l}+L_{\alpha \beta} \psi_{P M} \cos \theta_{e l}\right) / L_{2}, \\
a_{4}=\left(R L_{\alpha \beta}+\omega_{e l} L_{\alpha} L_{\beta}-\omega_{e l} L_{\alpha}^{2}-2 \omega_{e l} L_{\alpha \beta}^{2}\right) / L_{2}, \\
a_{5}=\left(-R L_{\alpha}-\omega_{e l} L_{\alpha} L_{\alpha \beta}-\omega_{e l} L_{\beta} L_{\alpha \beta}\right) / L_{2}, \\
a_{6}=\left(-L_{\alpha \beta} \psi_{P M} \sin \theta_{e l}-L_{\alpha} \psi_{P M} \cos \theta_{e l}\right) / L_{2},
\end{gathered}
$$

And the accessible stator currents $\left[i_{\alpha}, i_{\beta}\right]^{T}$ and the controlled voltages $\left[\begin{array}{ll}u_{\alpha} & u_{\beta}\end{array}\right]^{T}$ represent the input signals of the observer. The estimated state vector $\underline{x}=\left[i_{\alpha}, i_{\beta}, \omega_{e l}, \theta_{e l}\right.$, $\left.S_{d i s}\right]^{T}$ is calculated by using UKF [2]. For the estimation, the system equation should be transformed from the continuous-time system to the discrete-time system. More details can be found in (A1).

$$
\begin{gathered}
b_{1}=L_{\beta} / L_{2}, \quad b_{2}=-L_{\alpha \beta} / L_{2}, \\
b_{3}=-R L_{\alpha \beta} / L_{2}, \quad b_{4}=L_{\alpha} / L_{2}, \\
L_{\alpha}=L_{0}+L_{1} \cos 2 \theta_{e l}, \\
L_{\beta}=L_{0}-L_{1} \cos 2 \theta_{e l}, \\
L_{\alpha \beta}=L_{1} \sin 2 \theta_{e l}, \\
L_{0}=\left(L_{d}+L_{q}\right) / 2, \\
L_{1}=\left(L_{d}-L_{q}\right) / 2, \\
L_{2}=L_{\alpha} L_{\beta}-L_{\alpha \beta}^{2} .
\end{gathered}
$$

\section{Unscented Kalman Filter}

The Unscented Kalman Filter is an extension of the classical Kalman Filter and is based on the Unscented Transformation algorithm [15]. It is a deterministic approach, which makes use of the sigma points to calculate the mean and the approximate covariance matrix for the estimation of the non-linear system.

The linearization for non-linear system is not required in comparison to the Extended Kalman Filter (EKF). Sigma points are generated instead of calculating the Jacobian matrix of the non-linear observer model function [13]. The form of the UKF algorithm [7] consists of initialization, time update and measure update as shown in Fig.2:

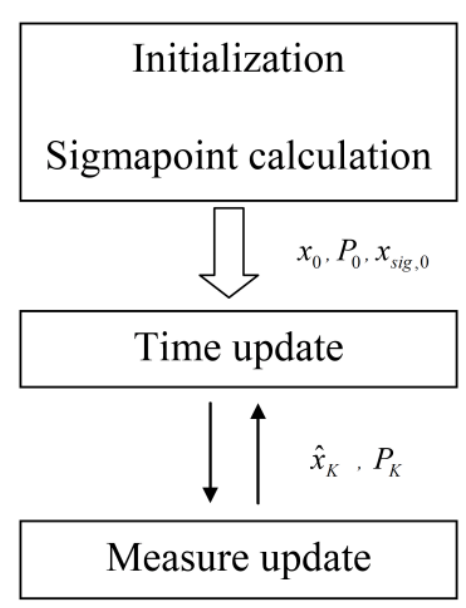

Fig. 2. Unscented Kalman Filter 
The initial value of the estimated state vector $\underline{x}=\left[i_{\alpha}, i_{\beta}, \omega_{e b}\right.$ $\left.\theta_{e l,} S_{d i s}\right]^{T}(21)$ and the covariance matrix of the mean $P_{0}(22)$ are defined as:

$$
\begin{aligned}
\hat{x}_{0}= & E\left[x_{0}\right]=\left[\begin{array}{lllll}
0 & 0 & 0 & 0 & 0
\end{array}\right]^{T}, \\
P_{0} & =E\left[\left(x_{0}-\hat{x}_{0}\right)\left(x_{0}-\hat{x}_{0}\right)^{T}\right] \\
& {\left[\begin{array}{lllll}
1 & 0 & 0 & 0 & 0 \\
0 & 1 & 0 & 0 & 0 \\
0 & 0 & 1 & 0 & 0 \\
0 & 0 & 0 & 1 & 0 \\
0 & 0 & 0 & 0 & 1
\end{array}\right] . }
\end{aligned}
$$

Afterward, $2 L+1$ sigma points, which represent the covariance and the true mean of the estimated vector $\underline{x}$, are created by (13).

$$
\begin{gathered}
\text { for } i=0, \quad x_{k-1}^{i}=\hat{x}_{k-1}, \text { with } \quad k \in\{1, \ldots, \infty\}, \\
\text { for } i=1 \ldots L, \quad x_{k-1}^{i}=\hat{x}_{k-1}+\gamma \sqrt{P_{k-1}}, \\
\text { for } i=L \ldots 2 L, \quad x_{k-1}^{i}=\hat{x}_{k-1}-\gamma \sqrt{P_{k-1}},
\end{gathered}
$$

where $L=5$ is the system dimension and

$$
\begin{gathered}
\gamma=\sqrt{(L+\lambda)}, \\
\lambda=\alpha^{2}(L+\kappa)-L .
\end{gathered}
$$

The computation of the function $\sqrt{P_{k-1}}$ can be realized by the Cholesky decomposition. The matrix $P_{k-1}$ must be positive-definite [9].

The created sigma points $x_{k-1}^{i}$ are inserted into the nonlinear system equation (14) (A1). Thereby, the updated sigma points $x_{i, k \mid k-1}^{*}$ for the next sample step can be calculated:

$$
x_{i, k \mid k-1}^{*}=f\left(x_{k-1}^{i}, u_{k-1}\right) .
$$

The sigma points $x_{i, k \mid k-1}^{*}$ are weighted by $W_{i}^{(m)}$ to determine the predicted estimated state vector $\hat{x}_{k}^{-}(14)$ [12]. The predicted estimated covariance matrix $P_{k}^{-}$can be calculated by

$$
\begin{gathered}
\hat{x}_{k}^{-}=\sum_{i=0}^{2 L} W_{i}^{(m)} x_{i, k \mid k-1}^{*}, \\
P_{k}^{-}=\sum_{i=0}^{2 L} W_{i}^{(c)}\left[x_{i, k \mid k-1}^{*}-\hat{x}_{k}^{-}\right]\left[x_{i, k \mid k-1}^{*}-\hat{x}_{k}^{-}\right]^{T}+Q,
\end{gathered}
$$

with the covariance matrix $Q$ the system noise (A2) and

$$
\begin{gathered}
W_{0}^{(m)}=\lambda /(L+\lambda), \\
W_{0}^{(c)}=\lambda /(L+\lambda)+\left(1-\alpha^{2}+\beta\right), \\
W_{i}^{(m)}=W_{i}^{(c)}=1 /(2(L+\lambda)) \text { for } i=0, \ldots, 2 L .
\end{gathered}
$$

The values of the noise distribution parameters $\alpha, \kappa, \beta$ are respectively $0.001,2$ and 0 [8]. A novel sigma points $x_{k \mid k-1}^{i-}$ are generated by predicted estimated state vector $\hat{x}_{k}^{-}$and estimated covariance matrix $P_{k}^{-}$:

$$
\begin{gathered}
\text { for } i=0, \quad x_{k \mid k-1}^{i-}=\hat{x}_{k}^{-}, \text {with } k \in\{1, \ldots, \infty\}, \\
\text { for } i=1 \ldots L, \quad x_{k \mid k-1}^{i-}=\hat{x}_{k}^{-}+\gamma \sqrt{P_{k}^{-}}, \\
\text {for } i=L \ldots 2 L, \quad x_{k \mid k-1}^{i-}=\hat{x}_{k}^{-}-\gamma \sqrt{P_{k}^{-}} .
\end{gathered}
$$

Such as $(13,14)$, the sigma points $x_{k \mid k-1}^{i-}$ are projected through the output equation (A1) and hence, the predicted output $\hat{y}_{k}^{-}$can be appointed by (19):

$$
\begin{gathered}
Y_{k \mid k-1}=h\left(x_{k \mid k-1}^{i-} u_{k-1}\right), \\
\hat{y}_{k}^{-}=\sum_{i=0}^{2 L} W_{i}^{(m)} Y_{i, k \mid k-1} .
\end{gathered}
$$

The output covariance matrix $P_{y_{k} y_{k}}$ and the covariance matrix $P_{x_{k} y_{k}}$ can be described as:

$$
\begin{gathered}
P_{y_{k} y_{k}}=\sum_{i=0}^{2 L} W_{i}^{(c)}\left[Y_{i, k \mid k-1}-\hat{y}_{k}^{-}\right]\left[Y_{i, k \mid k-1}-\hat{y}_{k}^{-}\right]^{T}+R, \\
P_{x_{k} y_{k}}=\sum_{i=0}^{2 L} W_{i}^{(c)}\left[x_{i, k \mid k-1}-\hat{x}_{k}^{-}\right]\left[Y_{i, k \mid k-1}-\hat{y}_{k}^{-}\right]^{T},
\end{gathered}
$$

where $R$ is the covariance matrix of the measurement noise. The value of $R$ can be found in (A2). Based on the Kalman Filter algorithm, the Kalman Gain $K_{k}$ can be derived from: 
Correction of the estimated state vector $\hat{x}_{k}^{-}$and the estimated covariance matrix $P_{k}^{-}$is done by:

$$
\begin{gathered}
K_{k}=P_{x_{k} y_{k}} P_{y_{k} y_{k}}^{-1} . \\
\hat{x}_{k}=\hat{x}_{k}^{-}+K_{k}\left(y_{k}-\hat{y}_{k}^{-}\right), \\
P_{k}=P_{k}^{-}-K_{k} P_{y_{k} y_{k}} K_{k}^{T},
\end{gathered}
$$

with the measured signal $y_{k}=\left[i_{\alpha, k}, i_{\beta, k}\right]^{T}$. The corrected $\hat{x}_{k}$ and $P_{k}$ will be used as start values for the next sample step. The algorithm of the time update and the measure update is recurrent [11].

\section{Experiment Results}

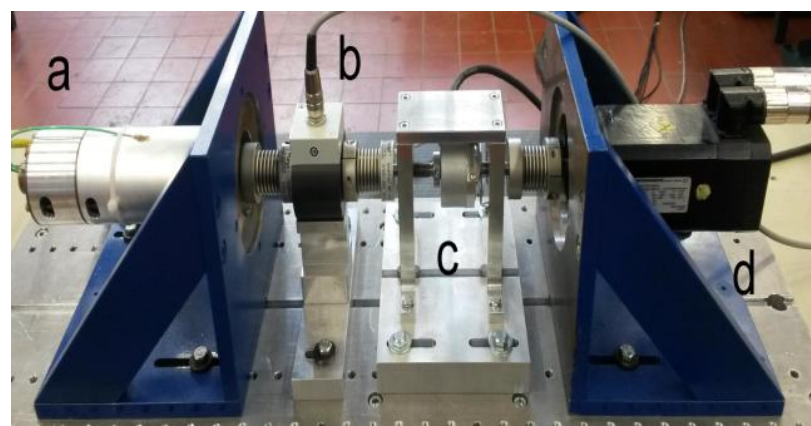

Fig. 3. Experimental test platform: mechanical setup

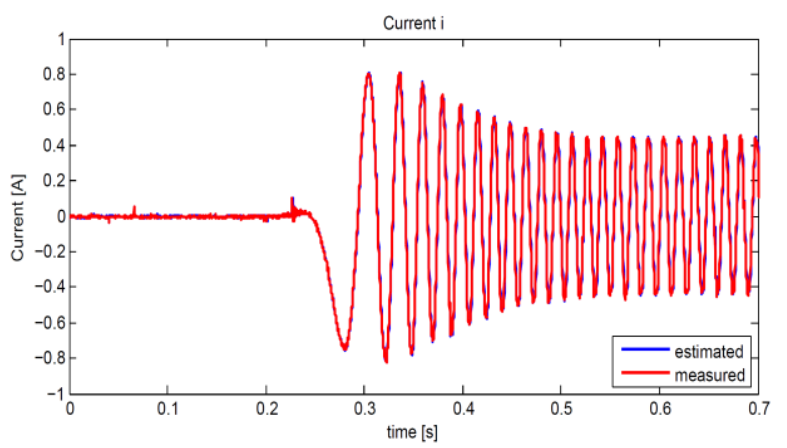

(a)

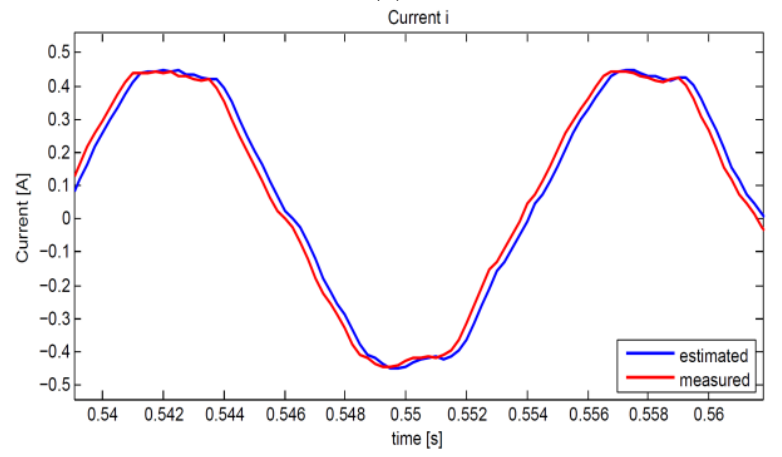

(b) zoom in

Fig. 4. Estimated and measured current at the speed of 100 $\mathrm{rad} / \mathrm{s}$

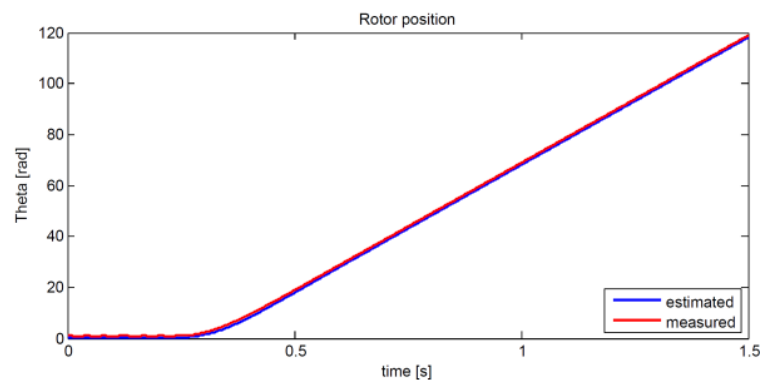

(a)

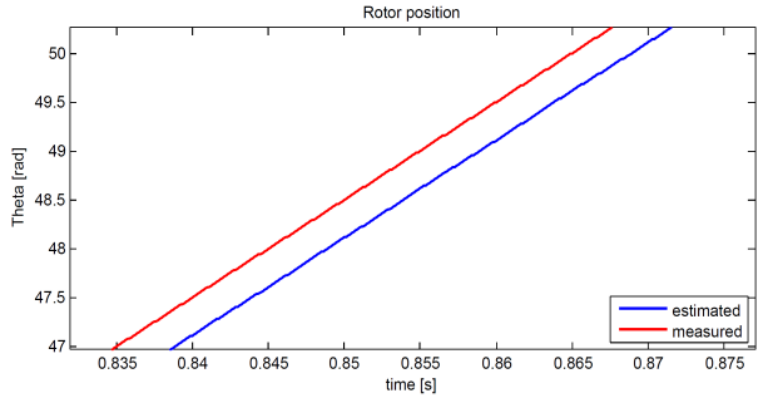

(b) zoom in

Fig. 5. Estimated and measured rotor position at the speed of $100 \mathrm{rad} / \mathrm{s}$

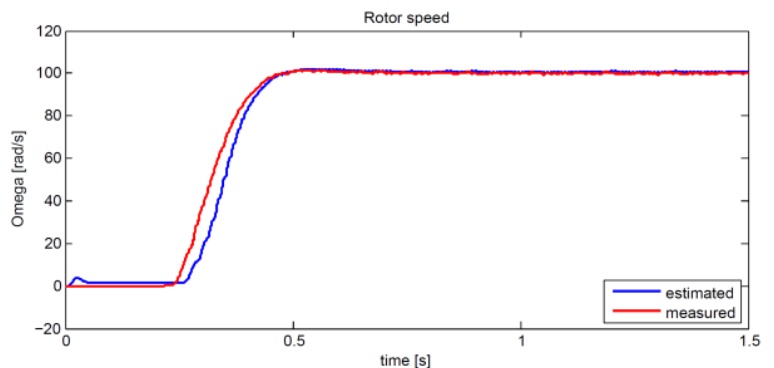

(a)

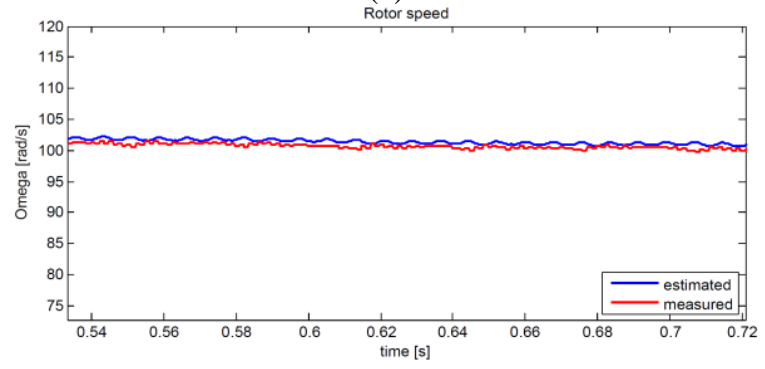

(b) zoom in

Fig. 6. Estimated and measured rotor velocity at the speed of $100 \mathrm{rad} / \mathrm{s}$

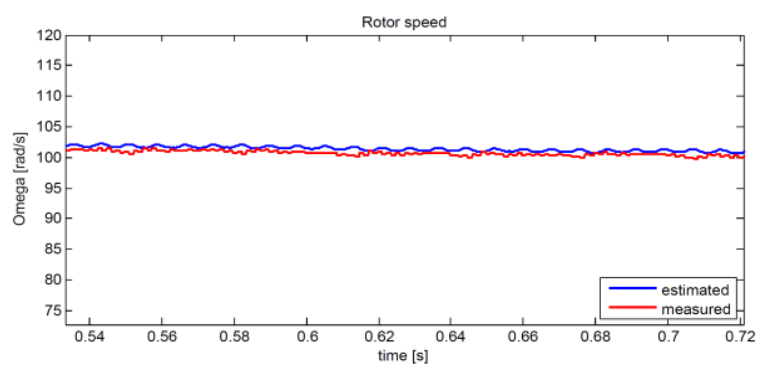

Fig. 7. Estimated disturbance value at the speed of 100 $\mathrm{rad} / \mathrm{s}$. 
In Fig. 3, the experimental system setup and testing setup with hardware components are illustrated. The above depicted UKF algorithm is implemented and explicated on a dSPACE platform for the interior permanent magnet synchronous machine (a). Thereby, a three-phase synchronous machine (d) is utilised as a load machine, which is controlled by an inverter in order to provide the desired torque [3]. An incremental rotary encoder (c) is used to compare the measure the rotor position and the rotor speed with the estimated values. A torque transducer (c) is used in order to get information of the Torque.

A dSPACE Rapid Control Prototyping is used to control the drive system. The parameters of the IPMSM and the load machine used in the simulation and experiment are tabulated in Tab. I and II. In contrast to the surface mounted permanent magnet synchronous motor (SPMSM), the stator inductances along quadrature axis and direct axis (Lq and Ld) of IPMSM are not identical.

The estimation result of the current of one phase at the speed of $100 \mathrm{rad} / \mathrm{s}$ is shown in Fig. 4a, where the measured current is illustrated. The chronological sequence of the measured current is similar to the estimated current. Thereby, it has a tiny time delay around merely one sampling time (Fig. 4b) to the measured current.

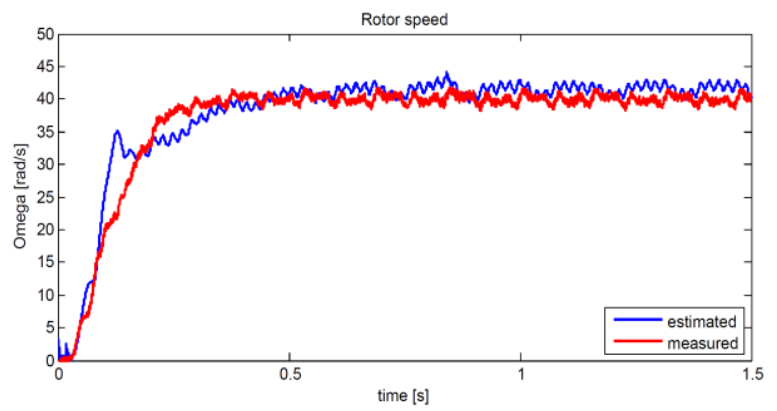

(a)

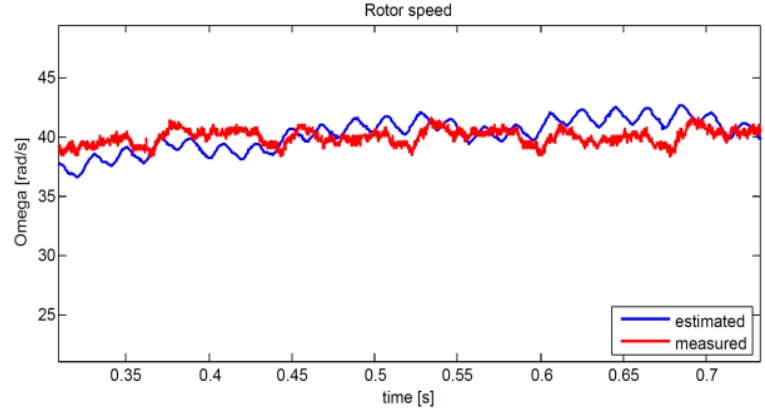

(b) zoom in

Fig. 8. Estimated rotor velocity at the speed of $40 \mathrm{rad} / \mathrm{s}$

Comparing the estimated rotor position and the measured rotor position from Fig. 5a, it can be observed that the curves of two signals are similar. The difference between the estimated and the measured rotor position amounts circ. $0.3 \mathrm{rad}$ because of a time delay of about $3 \mathrm{~ms}$.
Fig. 6a shows the estimation results of the rotor speed. The measured speed is set to $100 \mathrm{rad} / \mathrm{s}$. In the transient state, the estimated rotor speed is delayed in comparing to the measured rotor speed. The estimated rotor speed maintains nearly identical to the measured rotor speed in the steady state (Fig. 6b).

The estimated disturbance value is represented in Fig. 7. In the beginning, it shows a major modification. However, the estimated disturbance value approaches a constant value, when the UKF is stable.

More experiment results of different speeds are shown in Fig. 8 and Fig. 9. It can be concluded in Fig. 8b and Fig. 9b that the course of the estimated rotor speed is less noisy and smoother than the measured one. Thus, the UKF proves its filter character.

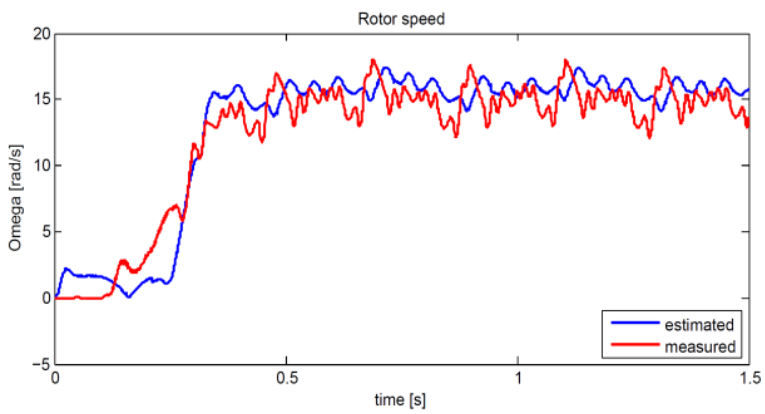

(a)

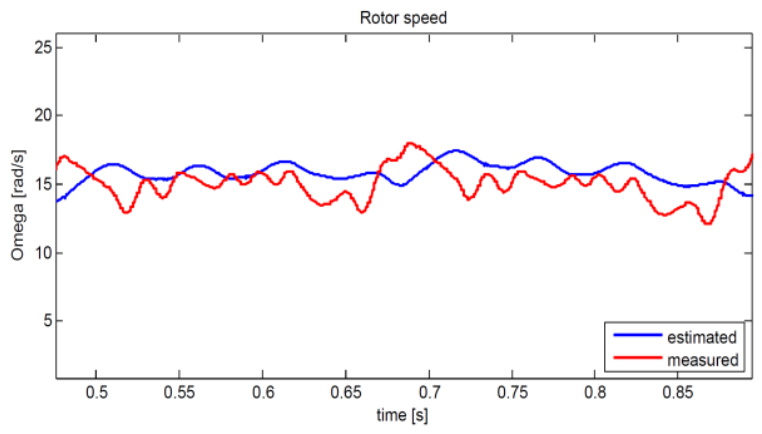

(b) zoom in

Fig. 9. Estimated rotor velocity at the speed of $15 \mathrm{rad} / \mathrm{s}$

\section{Conclusion}

In this paper an approach for rotor position and speed estimation of interior permanent magnet synchronous motor using Unscented Kalman Filter encoderless speed control is presented.

An extension of the observer system is developed. Thereby, the uncertainty of the system parameter is estimated as a disturbance value, in order that the estimation can be improved. The rotor position and rotor speed are well estimated. The results show improved stability and performance of the observer method by using extended IPMSM model. 


\section{Appendix}

Table 1. Specifications of IPMSM

\begin{tabular}{|l|l|}
\hline Parameters and constraints & Value \\
\hline Number of pole pairs $p$ & 4 \\
\hline Maximum speed $n_{\max }$ & $4000[\mathrm{rpm}]$ \\
\hline $\begin{array}{l}\text { Maximum permitted motor } \\
\text { current } I_{\max }\end{array}$ & $6.9[\mathrm{~A}]$ \\
\hline Rated motor current $I_{N}$ & $2.3[\mathrm{~A}]$ \\
\hline Rated torque $T_{N}$ & $3[\mathrm{Nm}]$ \\
\hline Mass moment of inertia J & $0.424 \cdot 10^{-4}[\mathrm{~kg} \cdot \mathrm{m} 2]$ \\
\hline Stator resistance $R$ & $3.0[\Omega]$ \\
\hline $\begin{array}{l}\text { Stator inductance } \\
\text { (quadrature axis) } L_{q}\end{array}$ & $0.0317[\mathrm{H}]$ \\
\hline $\begin{array}{l}\text { Stator inductance } \\
\text { (direct axis) } L_{d}\end{array}$ & $0.0286[\mathrm{H}]$ \\
\hline Excitation flux $\psi_{F}$ & $0.085[\mathrm{Vs}]$ \\
\hline Coefficient of friction B & 0 \\
\hline
\end{tabular}

Table 2. Specifications of Load Machine

\begin{tabular}{|l|l|}
\hline Parameters and constraints & Value \\
\hline Rated speed $n_{N}$ & $4500[\mathrm{rpm}]$ \\
\hline $\begin{array}{l}\text { Maximum permitted motor } \\
\text { current } I_{\max }\end{array}$ & $9.6[\mathrm{~A}]$ \\
\hline Rated motor current $I_{N}$ & $2.4[\mathrm{~A}]$ \\
\hline Rated torque $T_{N}$ & $2.0[\mathrm{Nm}]$ \\
\hline Maximum voltage $U_{\max }$ & $400[\mathrm{~V}]$ \\
\hline Rated motor frequency $f_{N}$ & $225[\mathrm{~Hz}]$ \\
\hline
\end{tabular}

Transformation from continuous-time system to discretetime system:

$$
\begin{aligned}
i_{\alpha, k+1}= & i_{\alpha, k}+\left(a_{1} i_{\alpha}+a_{2} i_{\beta}+a_{3} \omega_{e l}+b_{1} u_{\alpha}+b_{2} u_{\beta}\right) \cdot \Delta T \\
i_{\beta, k+1}= & i_{\beta, k}+\left(a_{4} i_{\alpha}+a_{5} i_{\beta}+a_{6} \omega_{e l}+b_{3} u_{\alpha}+b_{4} u_{\beta}\right) \cdot \Delta T \\
\omega_{e l, k+1} & =\omega_{e l, k}+\left\{\frac{3 p^{2}}{2 J}\left(\cos \theta_{e l} \cdot i_{\beta}-\sin \theta_{e l} \cdot i_{\alpha}\right)[\psi\right. \\
& \left.+\left(L_{d}-L_{q}\right)\left(\cos \theta_{e l} \cdot i_{\alpha}+\sin \theta_{e l} \cdot i_{\beta}\right)\right] \quad(\mathrm{A} 1) \\
& \left.-\frac{p}{J}\left(B \frac{\omega_{e l}}{p}+T_{l o a d}-S_{d i s}\right)\right\} \cdot \Delta T \\
\theta_{e l, k+1}= & \theta_{e l, k}+\omega_{e l} \cdot \Delta T \\
S_{d i s, k+1} & =S_{d i s, k}
\end{aligned}
$$

For the simulation and the experiment operations, the values of the covariance matrices $\mathrm{Q}$ and $\mathrm{R}$ were chosen:

$$
\begin{aligned}
& Q=\left[\begin{array}{ccccc}
5.9 \cdot 10^{-1} & 0 & 0 & 0 & 0 \\
0 & 2.354 \cdot 10^{-2} & 0 & 0 & 0 \\
0 & 0 & 1.3 & 0 & 0 \\
0 & 0 & 0 & 0.7 \cdot 10^{-7} & 0 \\
0 & 0 & 0 & 0 & 5.245 \cdot 10^{-4}
\end{array}\right] \\
& R=\left[\begin{array}{ccc}
1.0125 \cdot 10^{-3} & 0 \\
0 & 1.1325 \cdot 10^{-3}
\end{array}\right]
\end{aligned}
$$

\section{References}

[1] Vesely, L; Zamecnik, D., "Extending mathematical model of permanent magnet synchronous motors in alpha-beta coordinate system for EKF", Computational Intelligence and Informatics (CINTI), 2011 IEEE 12th International Symposium, pp 457 - 460, 21-22 Nov. 2011.

[2] Talla, J., Peroutka, Z."Neural network aided unscented Kalman filter for sensorless control of PMSM ", Power Electronics and Applications (EPE 2011), Proceedings of the 2011-14th European Conference, pp 1-9, Aug. 30 2011-Sept. 12011.

[3] An, L.; Franck, D,; and Hameyer, K.; "Sensorless control for surface mounted permanent magnet synchronous machines at low speed", ICEMS 2013 - International Conference on Electrical Machines and Systems, pages 77-82, 2013.

[4] Zdeněk, Peroutka.; Václav, Smídl; David Vosmik, "Challenges and Limits of Extended Kalman Filter based Sensorless Control of Permanent Magnet Synchronous Machine Drives", 2009 Power Electronics and Applications, IEEE, pp 1-11, Sept. 2009.

[5] Thomas, Herold; Enno, Lange; Kay, Hameyer, "Field-circuit coupled system simulation of a PMSM serbo drive and comparison with measurements", Electrical Machines (ICEM), IEEE, pp 1-5, September 2010.

[6] Borsje, P.; Chan, T.F.; Wong, Y.K.; Ho, S.L., "A Comparative Study of Kalman Filtering for Sensorless Control of a Permanent-Magnet Synchronous Motor Drive", Electric Machines and Drives, IEEE, pp 815-822, May 2005.

[7] Tze-Fun Chan; Pieter, Borsje; Weimin, Wang, "Application of Unscented Kalman Filter to Sensorless Permanent-Magnet Synchronous Motor Drive", Electric Machines and Drives Conference, pp 631-638, May 2009.

[8] Dariusz, Janiszewski, "Load torque estimation in sensorless PMSM drive using Unscented Kalmana Filter", Industrial Electronics(ISIE), IEEE, pp 643-648, June 2011.

[9] Dariusz, Janiszewski, "Disturbance estimation for sensorless PMSM drive with Unscented Kalman Filter", Advanced Motion Control(AMC), IEEE, pp 1-7, March 2012.

[10] Cheol, Moon; Kee Hyun Nam; Mun Kyn Jung; Chang Ho Chae; Young Ahn Kwon, "Sensorless Speed Control of Permanent Magnet Synchronous Motor Using Unscented Kalman Filter", SICE Annual Conference(SICE), IEEE, pp 2018-2023, August 2012.

[11] Dariusz, Janiszewski, "Unscented Kalman Filter for sensorless PMSM drive with output filter fed by PWM converter", IECON 2012-38th Annual Conference on IEEE Industrial Electronics Society, pp 4660-4665, October 2012. 
[12] A.Titaouine; D.Taibi; O.Bennis; F.Benchabane; R.Boumaraf; K.Yahia, "Adaptive Nonlinear Control Combined With Unscented Kalman Filter for Permanent Magnet Synchronous Motor Fed by AC/DC/AC Converter", Electrical Machines and Power Electronics and 2011 Electromotion Joint Conference(ACEMP), IEEE, pp. 26-31, September 2011.

[13] Dariusz, Janiszewski, "Load torque estimation for sensorless PMSM drive with output filter fed by PWM converter", Industrial Electronics Society, IECON 2013-39th Annual Conference of the IEEE, pp. 2953-2959, November 2013.

[14] Shinji Ichikawa; Mutuwo Tomita; Shinji Doki; Shigeru Okuma, "Sensorless Control of Permanent-Magnet Synchronous Motors Using Online Parameter Identification Based on System Identification Theory", IEEE Transactions on Industrial Electronics, Vol. 53, Nr.2, pp. 363-372, April 2006.

[15] Julier, S.J. and Uhlmann, J.K., "Unscented filtering and nonlinear estimation", Proceedings of the IEEE, Volume:92, Issue: 3, pp 401-422, Mar. 2004.

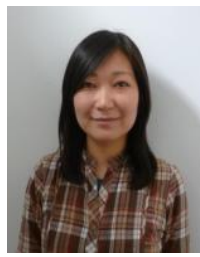

Lu An was born in Liaoning, China. She received the Dipl.-Ing. degree in electrical engineering from Gottfried Wilhelm Leibniz University Hannover, Hannover, Germany. She has been working as a research associate at the Institute of Electrical Machines of RWTH Aachen University, Germany since October 2009. Her research interests include sensorless control of permanent magnet synchronous machines.

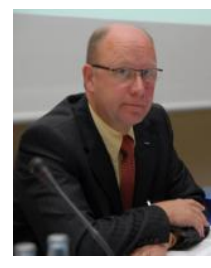

Kay Hameyer received the M.Sc. degree in electrical engineering from the University of Hannover, Hannover, Germany, and the Ph.D. degree from the University of Technology Berlin, Berlin, Germany. After his university studies, he was with Robert Bosch GmbH, Stuttgart, Germany, as a Design Engineer for permanent-magnet servo motors and electrical board net components for vehicles.

From 1996 to February 2004, he was a Full Professor of numerical field computations and electrical machines at the Katholieke Universiteit Leuven, Belgium. Since 2004 he is a Full Professor, the Director of the Institute of Electrical Machines, and the holder of the Chair Electromagnetic Energy Conversion at RWTH Aachen University, Aachen, Germany, where he has been the Dean of the Faculty of Electrical Engineering and Information Technology from 2007 to 2009.

His research interests are numerical field computation and optimization, the design and controls of electrical machines, in particular permanent magnet excited machines, induction machines and the design employing the methodology of virtual reality. Since several years Dr. Hameyer's work is concerned with the development of magnetic levitation for drive systems, magnetically excited audible noise in electrical machines and the characterization of ferro-magnetic materials.

Dr. Hameyer is author of more than 300 journal publications, more than 600 international conference publications and author of 4 books. Dr. Hameyer is a member of VDE, IEEE senior member, fellow of the IET. 